J. Clin. Chem. Clin. Biochem.

Vol. 27, 1989, pp. 419-421

(C) 1989 Walter de Gruyter \& Co.

Berlin - New York

\title{
Platelet and Plasma Serotonin in Patients with Liver Cirrhosis
}

\author{
By Bianca Marasini, Maria Luisa Biondi and A. Agostoni \\ Clinica Medica V, Ospedale S. Paolo, Università di Milano, Milano, Italia
}

(Received August 25, 1988/March 20, 1989)

Summary: To evaluate the role of serotonin in liver cirrhosis, serotonin was determined by high-performance liquid chromatography in plasma, platelets and ascitic fluids from 14 cirrhotic patients. Plasma-free serotonin was within the normal range, but intraplatelet serotonin was significantly low in cirrhosis $(p<0.001)$ and this decrease paralleled the severity of the disease. The concentration of serotonin in ascitic fluids was $12 \%$ of the corresponding plasma concentrations.

Our data indicate that serotonin levels are influenced by hepatic injury, but the reasons for these changes are still unclear.

\section{Introduction}

The hypersensitivity to serotonin of isolated mesenteric veins from portal hypertensive rats (1) and the beneficial haemodynamic effects of ketanserin, a selective inhibitor of serotonin ${ }_{2}$-receptors, in portal hypertensive animals and in patients with liver cirrhosis (2) prompted us to measure the concentrations of serotonin in plasma, platelets and ascitic fluid from cirrhotic patients, to determine whether serotonin might be involved in liver cirrhosis.

\section{Experimental}

Fourteen patients, with diagnoses of liver cirrhosis (8 alcoholic and 6 postnecrotic, mean age \pm S. D.: $61 \pm 11$ years) based on liver biopsy and/or on typical physical and laboratory findings, were studied.

Drugs affecting platelets and serotonin were discontinued at least 8 days prior to blood sampling. Thirteen healthy volunteers matched for age and sex served as normal controls.

Plasma and platelet serotonin was measured by high-performance liquid chromatography using an electrochemical detector.

Venous blood obtained without stasis was collected in $10 \mathrm{ml}$ tubes containing $3 \mathrm{mmol} / 1$ sodium EDTA, $50 \mathrm{nmol} / 1$ pargyline, $1 \mathrm{mmol} / \mathrm{l}$ theophylline, $5 \mathrm{nmol} / 1 \mathrm{imipramine}$ and $33 \mathrm{nmol} / 1 \mathrm{pros}-$ taglandin $\mathrm{E}_{1}$.

Platelet-rich plasma obtained by low speed centrifugation $(130 \mathrm{~g}, 10 \mathrm{~min})$ was diluted with platelet-poor plasma, obtained by higher speed centrifugation $(950 \mathrm{~g}, 10 \mathrm{~min})$ to yield platelet samples containing $110 \pm 20 \cdot 10^{9} / 1$. Intraplatelet or plasma serotonin was extracted following the method of Picard et al. (3). Briefly, to $0.1 \mathrm{ml}$ of platelet-rich plasma (subjected to ultrasonic treatment for $20 \mathrm{~s}$ ), or to $1 \mathrm{ml}$ of platelet-poor plasma, were added a fixed amount of internal standard (5hydroxy- $\mathrm{N}$-methyltryptamine), $1 \mathrm{ml}$ of buffer ( $\mathrm{pH} \mathrm{11}$, containing glycine, $0.1 \mathrm{~mol} / 1 \mathrm{NaOH}$ and $0.1 \mathrm{~mol} / 1 \mathrm{NaCl}$ ) and $5 \mathrm{ml}$ of chloroform/1-pentanol ( $60+20$, by vol., saturated with water).

Samples were shaken for $10 \mathrm{~min}$ and centrifuged $(2000 \mathrm{~g}, 10$ $\min )$. The organic phase was transferred to a second vial containing $400 \mu \mathrm{l} 0.1 \mathrm{~mol} / 1 \mathrm{HCl}$, shaken for $10 \mathrm{~min}$ and centrifuged $(2000 \mathrm{~g}, 10 \mathrm{~min})$. The aqueous phase was injected into the chromatograph.

The high-performance liquid chromatographic system consisted of a Perkin Elmer Series 2 pump (Perkin-Elmer, Norwalk, CT, U.S.A.), with a Model 7125 Rheodyne valve (Rheodyne, Berkely, CA, U.S. A.); a Nucleosil C18 column ( $5 \mu \mathrm{m} ; 150$ $\times 6 \mathrm{~mm}$ inside diameter), (Alltech Europe, Nazareth, Belgium); a Model 5100 A Coulochem detector (ESA Inc., Bedford, MA, U.S. A.) and a Model 561 Hitachi Recorder (Tokyo, Japan).

The mobile phase $(1 \mathrm{ml} / \mathrm{min}$, room temperature) consisted of $0.05 \mathrm{~mol} / 1$ acetate-citrate buffer $(\mathrm{pH} 4.6)$ containing $50 \mathrm{ml} / \mathrm{l}$ methanol. The average coefficient of variation of the method and the lowest limit of detection have been shown to be $3.5 \%$ and $1.2 \mathrm{nmol} / \mathrm{l}$, respectively (4).

Ascites drawn from five patients was processed as described for blood and assayed for serotonin.

Serotonin levels in patients and controls were compared with the aid of a paired Student t-test. Statistical differences between patient groups were established by use of one way variance analysis and the Scheffé multiple comparison test. Differences were considered significant when the two-tailed $p$ was less than 0.01 . 


\section{Results}

Platelets from cirrhotic patients contained significantly less serotonin than those from normal controls ( $p<0.001)$, while the levels of free circulating serotonin in the two groups were similar (tab. 1). We found no significant correlation between circulating and intraplatelet serotonin levels in patients or in controls, and none of the serotonin measurements correlated with the platelet count, serum albumin, ammonia, transaminase, immunoglobulins and creatinine, or the presence of cholostasis. However, patients with more severe disease - severity was graded by the Child criteria (5) - had significantly lower intraplatelet serotonin than patients with milder disease $(p<0.01)$. There were no significant differences in circulating serotonin (fig. 1). Neither circulating serotonin $(18.2 \pm 15.8$ vs $22.1 \pm 20.4 \mathrm{nmol} / \mathrm{l}$, mean \pm S. D. ) nor platelet serotonin $(2.5 \pm 0.8$ vs $2.6 \pm 2.2$ nmol $/ 10^{9}$ platelets) could distinguish alcoholic from postnecrotic cirrhosis. All the ascitic fluids had appreciable amounts of serotonin, representing $12 \%$ of the corresponding plasma values (tab. 1). One value, from a haemorrhagic fluid, was $140 \%$ of the corresponding plasma level (17.0 and $12.5 \mathrm{nmol} / \mathrm{l}$, ascites and plasma), and this was not included in the calculations of table 1.

Tab. 1. Concentrations (mean \pm S. D.) of serotonin in plasma, platelets and ascites from cirrhotic patients and healthy controls.

\begin{tabular}{llll}
\hline & $\begin{array}{l}\text { Plasma } \\
(\mathrm{nmol} / \mathrm{l})\end{array}$ & $\begin{array}{l}\text { Platelets } \\
\left(\mathrm{nmol} / 10^{9} \text { platelets }\right)\end{array}$ & $\begin{array}{l}\text { Ascites } \\
(\mathrm{nmol} / \mathrm{l})\end{array}$ \\
\hline Cirrhotics & $19.9 \pm 17.0$ & $2.5 \pm 1.6\left(^{*}\right)$ & $3.4 \pm 1.7$ \\
Controls & $15.0 \pm 6.2$ & $4.6 \pm 1.2$ & \\
\hline
\end{tabular}

(*) $\mathrm{p}<0.001$ (patients vs controls)
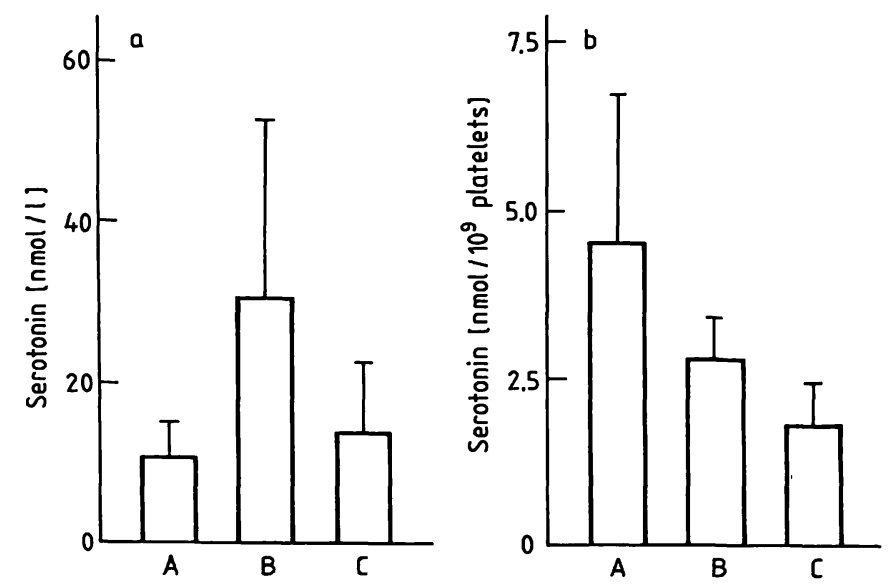

Fig. 1. Circulating (plasma, a) and intraplatelet (b) serotonin levels (mean \pm S. D.) from cirrhotic patients grouped upon the Child-Turcotte criteria A, B, C.

$A$ indicates the mildest hepatic injury and $C$ the most severe.

The differences in plasma values are not significant. For intraplatelet values A vs. $C$ is significant at $p<0.01$.
The concentration of serotonin in ascites was independent of the plasma and intraplatelet serotonin contents and of the levels of proteins, glucose, alkaline phosphatase, amylase or urea in the ascitic fluid.

\section{Discussion}

Until now, no data have been published on plasma free serotonin in liver diseases. Low intraplatelet serotonin was previously observed by Ahtee et al. in a small number of patients with alcoholic liver cirrhosis, and considered to be due to reduced platelet serotonin uptake $(6,7)$. However, reduced uptake should lead to increased concentrations of free serotonin in plasma, but free serotonin was found to be within the normal range in the plasma of our patients. However, a number of factors might influence the concentration of circulating serotonin in cirrhotics, e.g. the by-pass of portal blood in systemic circulation, an altered serotonin catabolism due to increased monoaminoxidase activity (8), an abnormal availability of free tryptophan, the precursor of serotonin (9). The wide range of circulating serotonin found in cirrhotics might well be the result of a large number of different contributing factors. Free serotonin levels are thus not representative of the extent of hepatic injury. The low intraplatelet serotonin and, more significantly, the fact that platelet serotonin decreased as the severity of liver disease increased, are difficult to explain. It has been reported that platelet uptake of serotonin is reduced in liver cirrhosis $(6,7)$, but the mechanism for this is not known, even though metabolic factors or altered serotonin receptors can be hypothesized (7).

The normal concentration of free serotonin (free serotonin is the active form of serotonin) found in cirrhotic plasma does not indicate a role for ketanserin in liver cirrhosis. On the other hand, the observation that platelets containing low serotonin are more responsive to serotonin-induced aggregation in vitro (10) and the abnormal vascular sensitivity to serotonin of mesenteric veins from portal hypertensive rats (1) might indicate a role for such serotonin receptor $^{2}$ antagonists in liver disorders.

In conclusion, our data indicate that:

1) intraplatelet serotonin levels are influenced by hepatic cirrhosis and

2) intraplatelet but not circulating serotonin is an index of the severity of hepatic damage.

The factors underlying this observation, and the question of whether it can be influenced by ketanserin require further study. 


\section{References}

1. Cummings, S. A., Groszmann, R. J. \& Kaumann, A. J. (1986) Hypersensitivity of mesenteric veins to 5-hydroxytryptamine and ketanserin-induced reduction of portal pressure in portal hypertensive rats. Br. J. Pharmac. 89, $501-513$.

2. Hadengue, A., Lee, S. S., Moreau, R., Braillon, A. \& Lebrec, D. (1987) Beneficial hemodynamic effects of ketanserin in patients with cirrhosis: possible role of serotonergic mechanism in portal hypertension. Hepatology 7, 644647.

3. Picard, M., Olichon, D. \& Gombert, J. (1985) Determination of serotonin in plasma by liquid chromatography with electrochemical detection. J. Chromat. 341, 445-451.

4. Marasini, B., Biondi, M. L., Pietta, P. \& Agostoni, A. (1985) High-performance liquid chromatographic assay of serotonin in plasma. La Ricerca Clin. Lab. 15, 63-69.

5. Child III, C. G. \& Turcotte, J. G. (1964) The liver and portal hypertension. In: Surgery and portal hypertension (Child III, C. G., ed.) WB Sounders Co., Philadelphia, p. 50.
6. Ahtee, L., Pentikäinen, L., Pentikäinen, P. J. \& Paasonen, M. K. (1974) 5-hydroxytryptamine in the blood platelets of cirrhotic and hypertensive patients. Experientia 30, $1328-1329$.

7. Ahtee, L., Briley, M., Raisman, R., Lebrec, D. \& Langer, S. Z. (1981) Reduced uptake of serotonin but unchanged $\mathrm{H}$-imipramine binding in the platelet from cirrhotic patients. Life Sci. 29, 2323-2329.

8. Gressner, A. M., Roebruck, P. \& Tittor, W. (1982) Validity of monoamine oxidase in serum for diagnosis of liver cirrhosis: estimation of predictive values, sensitivities and specificities. J. Clin. Chem. Clin. Biochem. 20, 509-514.

9. Rössle, M., Herz, R., Mullen, K. D. \& Jones, D. B. (1986) The disposition of intravenous L-tryptophan in healthy subjects and in patients with liver disease. $\mathrm{Br}$. J. Clin. Pharmac. 22, 633-638.

10. Hilton, B. P. \& Cumings, J. N. (1971) An assessment of platelet aggregation induced by 5 -hydroxytryptamine. J. Clin. Pathol. 24, 250-258.

Bianca Marasini, M.D.

Clinica Medica V

Ospedale S. Paolo

Via di Rudinì 8

I-20142 Milano 


i)

